\section{Mucosubstances in the porcine gastrointestinal tract: Fixation, staining and quantification}

\author{
Juliane Rieger, Barbara Drewes, \\ Hana Hünigen, Johanna Plendl \\ Department of Veterinary Medicine, \\ Institute of Veterinary Anatomy, Freie \\ Universität Berlin, Germany
}

\begin{abstract}
Mucins are of great interest in intestinal research and histochemical methods are often employed to identify them. Since it is in the nature of mucins that they are "hard to hold onto" once they come into contact with water, a frequently used medium in histochemistry, there are a number of challenges that may decrease diagnostic accuracy. As the outcome of methods published for microscopic detection of mucosubstances proved to be unsatisfactory in our hands, the aim was the establishment of a reliable and reproducible protocol. Tissue samples were available from pig feeding experiments. In the present study, we focus on a fixation / staining procedure without making comparisons between differently fed pigs. Several fixation and staining procedures were evaluated for their use in semiautomatic quantification and quality assessment of different mucus fractions simultaneous on one tissue section. Cryostat sectioning, subsequent fixation steps with heat, ethanol and modified Bouin's solution, followed by triple staining with high iron diamine, alcian blue and periodic acid-Schiff turned out to be the best method to identify sulfomucin, sialomucin and neutral mucin simultaneous on one tissue section. This methodology resulted in very good morphology of goblet cells with intact mucin containing vesicles within the cells, which was comparable to ultrastructural electron microscopical observations. Semiautomatic quantification of different mucins was possible. In conclusion, reliable mucus quantification and assessment of mucus quality requires strictly tested procedures. According to our experience, the most important aim after cryosectioning is fast fixation of the mucosubstances, which requires a combination of different fixation steps.
\end{abstract}

\section{Introduction}

Mucus, which is build-up of large glycoproteins called mucins and secreted from diverse epithelial cells throughout the gas- trointestinal tract, is of great interest in gastrointestinal research. Its barrier building capacity represents one of the key mechanisms ensuring the protection of the mucosa from harmful as well as benign microbiota by preventing their translocation into the tissue. ${ }^{1}$ Johansson and colleagues ${ }^{2}$ elegantly showed that upon excretion from the cells, the mucins bind water and swell - this way forming the final mucus gel. According to them, this mucus is arranged in a 3D meshlike structure with a high viscosity, which diminishes with increasing distance from the epithelial surface and mixing with water. They demonstrated that after secretion, the mucus is organized into a firmly adherent layer that shows a stratified appearance. The firmly adherent layer is converted via proteolysis into a loose mucus layer which expands in volume. ${ }^{2}$ The organization of these layers is different throughout the gastrointestinal tract. Glandular stomach and colon have the aforedescribed two-layered system, whereas in the small intestine only a single and loosely attached layer can be found. ${ }^{3}$

Since the mucin composition in the gut may be altered by several factors, amongst them nutritional ones, ${ }^{4-6}$ it is of interest how various treatments influence the mucin composition of different sections of the gastrointestinal tract in the pig and to investigate possible changes via histochemistry. Despite advantages like the cost efficacy of using histochemical methods to demonstrate the mucin composition of a chosen tissue, there are a number of challenges and downsides that may decrease diagnostic accuracy and lead to results that are not reproducible. It is in the nature of mucins that they are "hard to hold onto" once they come into contact with water, a frequently used medium in histochemistry. As the outcome of methods available for direct microscopic detection of mucins proved to be unsatisfactory, the aim was the establishment of a protocol with the foremost aim to quantify goblet cells and, at the same time, evaluate their histochemically distinguishable mucin content. Tissue samples were available from animals killed in experiments actually aimed at investigating diet effects on the gastrointestinal tract. In the present study, we focus on a fixation / staining procedure without making comparisons between differently fed pigs. Our guiding research question was: "What is the natural appearance of mucins in the cell?". In a first step, this question should be answered by examining the morphology of goblet cells in electron microscopical samples. Second, if the natural appearance of mucins inside the cell should be studied, frozen sections may be superior to paraffin embedded samples for several reasons. The most important is that
Correspondence: Juliane Rieger, Department of Veterinary Medicine, Institute of Veterinary Anatomy, Freie Universität Berlin, Koserstraße 20, 14195 Berlin, Germany.

Tel. +49.30.83853483 - Fax: +49.30.838453483. E-mail: Juliane.Rieger@fu-berlin.de

Key words: Goblet cells; mucin; intestine; stomach; histochemistry.

Contributions: JR, study conception and design, critical literature review, data acquisition, analysis and interpretation, manuscript drafting and final approval; BD, study conception and design, data acquisition, analysis and interpretation, critical review of the manuscript and final approval; HH, study conception and design, data analysis and interpretation, critical review of the manuscript and final approval; JP, study conception and design, data analysis and interpretation, critical review of the manuscript and final approval.

Conflict of interest: The authors declare that there is no conflict of interest that could be perceived as prejudicing the impartiality of the research reported.

Acknowledgments: The authors would like to thank Prof. P. Böck (University of Veterinary Medicine, Vienna, Austria) as well as K. Briest-Forch (Institute of Veterinary Anatomy, Freie Universität Berlin, Germany) for valuable advice considering histochemical techniques.

Funding: This study was in part supported by the German Research Foundation (DFG) Collaborative Research Centre 852 "Nutrition and intestinal microbiota - host interactions in the pig" (Grant no. SFB852/1). The authors acknowledge support by the German Research Foundation and the Open Access Publication Fund of the Freie Universität Berlin.

Received for publication: 22 March 2019. Accepted for publication: 10 June 2019.

This work is licensed under a Creative Commons Attribution-NonCommercial 4.0 International License (CC BY-NC 4.0).

${ }^{\circ}$ Copyright: the Author(s), 2019

Licensee PAGEPress, Italy

European Journal of Histochemistry 2019; 63:3030 doi:10.4081/ejh.2019.3030

the main component of mucus is water, which will be lost during fixation, dehydration and paraffin embedding and cause the tissue and mucus to shrink considerably. $3,7,8$ We therefore aimed at establishing a protocol using frozen sections in which the intestinal goblet cell vesicles were supposed to preserve their natural morphological properties. 


\section{Materials and Methods}

\section{Transmission electron microscopy}

Porcine intestinal samples for electron microscopy were available from our tissue archive from a previous trial. In short, they were rinsed in ice cooled Ringer solution and cut open on the mesenterial side; $2 \times 2 \times 2$ mm small pieces were fixed in Karnovsky's fixative for $24-48 \mathrm{~h}$ at $4{ }^{\circ} \mathrm{C}$, washed with sodium cacodylate buffer, treated with osmium tetroxide and washed again. Samples were dehydrated in increasing ethanol series and propylene oxide and resin-embedded. The resin was allowed to polymerize at 45 and $60^{\circ} \mathrm{C}$ for $24 \mathrm{~h}$ each. 70-nm ultrathin sections were cut and contrasted with uranyl acetate and lead citrate. Images were taken using a transmission electron microscope (EM 902 A, Zeiss, Oberkochen, Germany)

\section{Intestinal tissue sampling}

Histological samples were obtained during necropsy of piglets (breed: German Landrace or (Landrace x Duroc) x Pietrain cross; fattening period from 20 to $45 \mathrm{~kg}$ of body weight) from various feeding trials. Experimental approval was given by the local authority / Regional Office for Health and Social Affairs Berlin (Landesamt für Gesundheit und Soziales, Berlin). IDs: G0348/09 and A0100/13. Different sampling, fixation and staining procedures were evaluated for their use in semiautomatic quantification and quality assessment of different mucus fractions simultaneous on one tissue section. Tissue sections for histochemistry were taken from different parts of the gastrointestinal tract. The sections were not rinsed. The stomach was opened at the curvatura major and $2 \times 2 \mathrm{~cm}$ pieces were taken from the cardiac, fundic and pyloric region. Sections of the small intestine $(2 \mathrm{~cm}$ length) where taken from the duodenum (ca. $15 \mathrm{~cm}$ ahead of the plica duodenocolica), jejunum (ca. $1 \mathrm{~m}$ after the plica duodenocolica) and ileum (ca. $10 \mathrm{~cm}$ after the beginning of the plica ileocaecalis) without opening the intestine. The samples were placed in embedding molds (Peel-A-Way ${ }^{\circledR}$ Disposable Molds, VWR International $\mathrm{GmbH}$, Darmstadt, Germany), covered with cryo-embedding medium (Tissue-Tek* O.C.T. Compound, VWR International $\mathrm{GmbH})$, frozen in liquid nitrogen and stored at $-80^{\circ} \mathrm{C}$ in plastic sampling bags.

\section{Histochemistry}

The finally successful protocol is described in the following section. A complete protocol with special emphasis on the staining procedure is given in Table 1 . Several other fixation protocols recommended for the histochemical detection of mucosubstances were tested (paraformaldehyde vapour, $4 \%$ formalin in PBS, ethanolic formalin according to Harrison, Carnoy, absolute ethanol, modified lead acetateethanol-acetic acid according to Mota, formol-Bouin mixture; Table 2). Sections of $7 \mu \mathrm{m}$ were cut from the frozen tissue blocks with a cryo-microtome (Microm HM 560, Microm International $\mathrm{GmbH}$, Dreieich,

Table 1. Fixation and staining protocol used in this study to identify mucosubstances. Special attention is paid to the staining process.

\section{Fixation}

- $7 \mu \mathrm{m}$ cryostat sections are placed on preheated $\left(50^{\circ} \mathrm{C}\right)$ slides (e.g. silanized) and immediately air dried at $50^{\circ} \mathrm{C}$ for at least $30 \mathrm{~min}$

Immediate drying is crucial for the result!

- Slides are allowed to cool to room temperature (RT) and then set in pre-cooled anhydrous ethanol $\left(-80^{\circ} \mathrm{C}\right)$ for $1 \mathrm{~h}$ at $-80^{\circ} \mathrm{C}$

- The slides are directly moved to Bouin modified according to Gendre (Romeis 17th ed., 4-6.2.5.2.2)9 and further fixed overnight at RT

- The fixing reagent is rinsed out in $96 \%$ ethanol two times for $15 \mathrm{~min}$ and for further 10 min each in $80 \%$ and $70 \%$ ethanol

- Further rinsing is carried out in demineralized water for 30 min and then in bi-distilled water $\left(\mathrm{ddH}_{2} \mathrm{O}\right)$ for 2 min

- The slides are immediately used or air dried at $50^{\circ} \mathrm{C}$ and stored at RT

1. HID solution:

(solution is $2 \frac{1}{2}$ times higher concentrated as in many literature citations!)

a. $480.0 \mathrm{mg}$ N,N-Dimethyl-m-phenylenediamine dihydrochlorid (CAS-Nr. 3575-32-4; Sigma 219223-5G) and

b. 80.0 mg N,N-Dimethyl-p-phenylenediamine.HCl (N,N-Dimethyl-p-phenylene-diamine hydrochloride; CAS-Nr. 2052-46-2; Sigma D5004-10G) are solved in

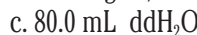

d. $5.6 \mathrm{~mL} 37 \% \mathrm{FeCl}_{3}$-solution is added (CAS-Nr. 7705-08-3; Merck) $(=2.072 \mathrm{~g} / 5.6 \mathrm{~mL})$

- It is difficult to accurately weigh the $\mathrm{FeCl}_{3}$ quantities actually needed because the substance is sticky. Therefore, it is better to weigh a bit more and adjust the amount of $\mathrm{ddH}_{2} \mathrm{O}$. Finally, take out the $5.6 \mathrm{~mL}$ and discard the rest. Solution gets hot! Prepare solution fresh!

- Put slides directly in staining solution, staining $18 \mathrm{~h}-21 \mathrm{~h}$ at RT in the dark. It can be used even after days

- $\quad$ Rinse slides in $\mathrm{ddH}_{2} \mathrm{O} 3 \times 2$ min

2. $\mathrm{AB} 2,5$

- $\quad$ Rinse slides in $3 \%$ acetic acid for 3 min

- Incubation in AB2.5 2h at RT (Alcian blue 8GX [Chroma 1A 288] 1\% dissolved in 3\% acetic acid. Not all dye batches are suitable! The dye of Chroma has been found to be well suited)

- $\quad$ Rinse slides in $3 \%$ acetic acid for about $30 \mathrm{~s}$

- Rinse slides in $\mathrm{ddH}_{2} \mathrm{O}$ for $2 \times 3$ min

3. PAS-reaction

- Incubation in $1 \%$ aqueous periodic acid 10 min at RT (prepare solution fresh!)

- Rinse slides in $\mathrm{ddH}_{2} \mathrm{O}$ for $3 \times 2$ min

- Incubation in Schiff's reagent $\sim 5$ min at RT in the dark (under visual control)

- Rinse slides in tap water for $15 \mathrm{~min}$

- Rinse slides in $\mathrm{ddH}_{2} \mathrm{O}$ for $2 \mathrm{~min}$

- Pre-dry sections with filter paper and allow to air dry at $50^{\circ} \mathrm{C}$ for at least $30 \mathrm{~min}$

- Briefly dive slides in xylene and cover 
Germany), put on preheated $\left(50^{\circ} \mathrm{C}\right)$ slides and immediately allowed to dry on a heating plate at $50^{\circ} \mathrm{C}$ for $1 \mathrm{~h}$. The dried tissue sections were fixed for $1 \mathrm{~h}$ in $100 \%$ ethanol at $-80^{\circ} \mathrm{C}$. Directly from the ethanol they were fixed overnight in a modified alcoholic Bouin's solution (Bouin mod. n. Gendre $^{9}$ ). The sections were rinsed in a descending series of ethanol and distilled water and dried on a heating plate at $50^{\circ} \mathrm{C}$ for later use. To demonstrate different mucin types distinguished by the carbohydrates present, a triple staining was used..$^{10}$ Sections were stained first with high iron diamine (HID), ${ }^{11}$ which stains sulfomucin in a brownish-purple to black colour. Second, the sections were stained with Alcian blue at pH 2.5 (AB) identifying sialomucin in turquoise. The third staining step was the periodic acid-Schiff (PAS) reaction, staining neutral mucin magenta. Mixtures of the mucin types could be distinguished by the respective combined colours. A mixture of neutral and sulfated mucin stains magenta with a brown shade, a mix of neutral and sialic mucin stains violet and a mix with a high content of sialic mucin and a small amount of neutral and/or sulfomucin stains cornflower blue. ${ }^{12}$

\section{Quantification of goblet cells and mucin types}

For each sample 2 slides were prepared and parameters were evaluated under a light microscope (Axioplan, Carl Zeiss, Jena, Germany). Digitalized live pictures were transferred and analysed on a monitor with the help of the computer assisted image analysis program NIS-Elements AR (Nikon Instruments Inc., Melville, NY, USA). In the small intestine, mucin types and goblet cell numbers were evaluated in an area covering the crypt area and the base of the villi. In the stomach, the mucosa of the pyloric region was analysed. Measurements were
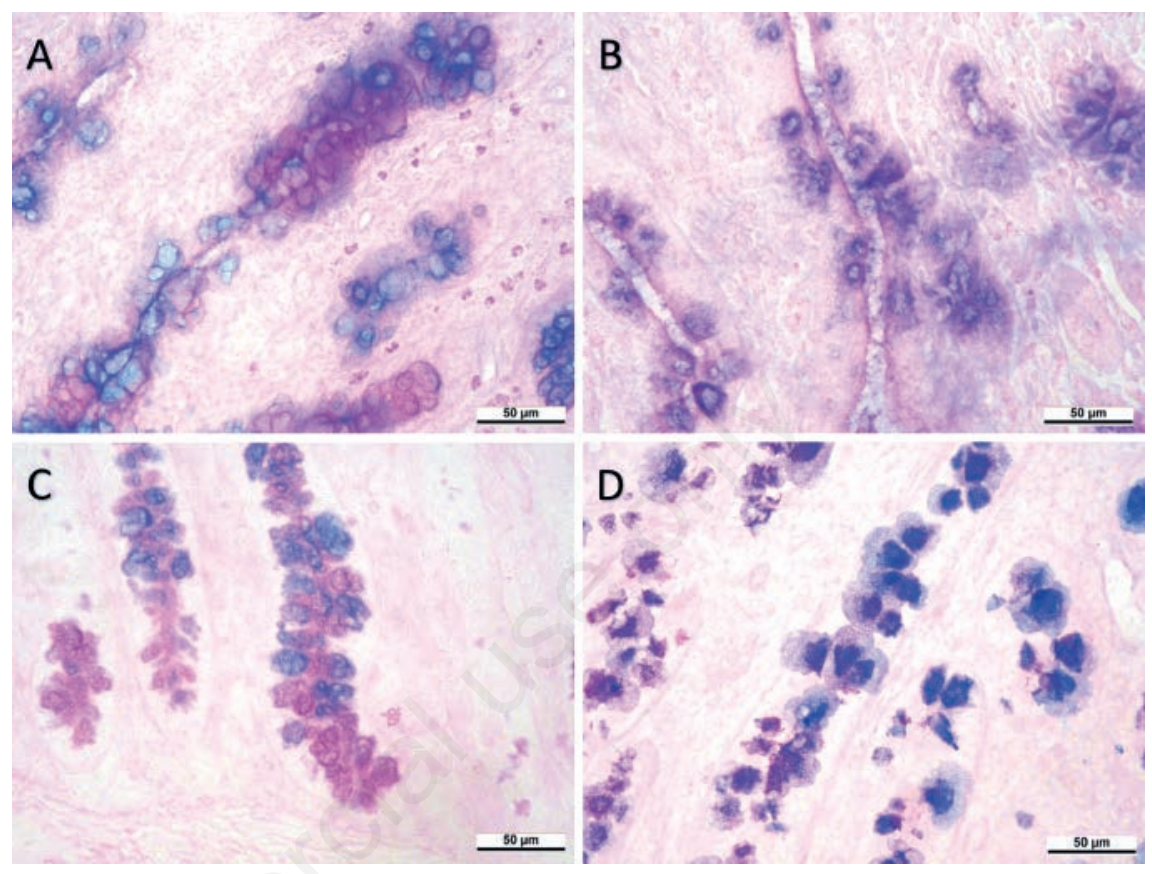

Figure 1. Examples for suboptimal fixation after cryostat sectioning and AB/PAS staining. Mucus can be seen leaking out of the goblet cells. A) Formalin. B) Formalin + Bouin. C) Drying + Formalin + Bouin. D) $100 \%$ ethanol $-70^{\circ} \mathrm{C}$. made in areas, where most intestinal crypts or stomach glands were cut longitudinally. Ten randomly selected high power fields per sample were measured at a total magnification of 200x. The total number of goblet cells and the area they occupied in the mucosa was identified automatically via their combined staining colour by means of

Table 2. Overview of other fixation protocols tested in this study, specifically recommended by other authors for the detection of mucosubstances.

Other tested fixation protocols

Formaldehyde vapor ${ }^{31}$

-> staining cuvette laid out with paper $+20 \mathrm{~mL} 37 \%$ formalin + slides placed over in dyeing bank; alternatively 1 spoon of paraformaldehyde on the bottom of the jar, covered by piece of paper

$4 \%$ formalin in $\mathrm{PBS}^{9,32}$

-> formalin 37\% in PBS, pH 7.4

Ethanolic formalin according to Harrison ${ }^{33}$

$->$ formalin $37 \% 21.6 \mathrm{~mL}+$ ethanol $100 \% 120 \mathrm{~mL}+\mathrm{NaCl} 0,9 \mathrm{~g}$

$+\mathrm{ddH}_{2} \mathrm{O}$ ad $200.0 \mathrm{~mL}$

\begin{tabular}{|c|c|}
\hline \multirow{2}{*}{\multicolumn{2}{|c|}{ Carnoy $^{9,3}$}} \\
\hline & \\
\hline Absolute ethanol ${ }^{9,28}$ & Mucus leaking out of goblet cells, forming foamy halos around them \\
\hline $\begin{array}{l}\text { Lead acetate-ethanol-glacial acetic acid } \\
\text { modified according to Mota (modified again: lead acetate 1\%) } \\
\quad \text { - lead acetate } \times 3 \mathrm{H}_{2} \mathrm{O} 1.5 \mathrm{~g}+\mathrm{ddH}_{2} \mathrm{O} 73.5 \mathrm{~mL}+\text { ethanol } 100 \% 60.0 \mathrm{~mL}+ \\
\quad \text { formalin } 37 \% 15.0 \mathrm{~mL}+\text { glacial acetic acid } 1.5 \mathrm{~mL}\end{array}$ & $\begin{array}{l}\text { Hardly any shrinkage, mucin granules often intact but some leakage of } \\
\text { mucus to surrounding tissue, poor dyeability of alcian blue components }\end{array}$ \\
\hline $\begin{array}{l}\text { Formalin / Bouin } 36 \\
\text { 1. Formalin } 4 \% \text { in } \mathrm{ddH}_{2} \mathrm{O} \\
\text { 2. Bouin ( } 80 \mathrm{~mL} \text { saturated aqueous picric acid }+20 \mathrm{~mL} \text { formalin } 37 \% \\
+5 \mathrm{~mL} \text { glacial acetic acid) }\end{array}$ & $\begin{array}{l}\text { Dyeable mucus not limited to goblet cells but forming cloudy halos around } \\
\text { them, empty granular structures to recognize within the goblet cells }\end{array}$ \\
\hline
\end{tabular}


threshold classification for the small intestinal samples. The different mucin types were identified automatically via their different staining colour by means of pixel classification.

The following parameters resulted from these measurements:

- area occupied by goblet cells in \%

goblet cells per $1 \mathrm{~mm}^{2}$

- area covered by mucin type in $\mu \mathrm{m}^{2} / 1 \mathrm{~mm}^{2}$

- neutral mucus [PAS (magenta)]

- sulfomucin [HID (brown)]

- sialomucin [AB (turquoise]

- mixed mucus - neutral + sulfomucin [PAS + HID (magenta with brown shade)]

mixed mucus - neutral + sialomucin [PAS + AB (violet) $]$

mixed mucus - sialomucin + neutral /sulfomucin [AB + PAS/HID (cornflower blue)]

\section{Results}

Fixation and staining procedures according to a published protocol, ${ }^{7}$ including several variations and recommendations according to other protocols (Table 1) resulted in the mucins to leak out of the goblet cells, forming a foamy staining halo around them (Figure 1). In our hands, the best results were obtained with cryostat sectioning, subsequent fixation steps with heat, ethanol and modified Bouin's solution, followed by triple staining with $\mathrm{HID}, \mathrm{AB}$ and PAS. This procedure turned out to be the best method to identify sulfomucin, sialomucin and neutral mucin simultaneous on one tissue section (Figure 2). It resulted in very good morphology of the goblet cells with the membrane-surrounded mucin droplets still intact within the cells. Pictures show examples from the small intestine (Figure 3). Morphology shown in light microscopic pictures resembled ultrastructural electron microscopical observations (Figure 3D). Mucins in stomach samples were found to be well preserved (Figure 2 A-C). The final protocol also turned out well for automatic measurement. The total number of goblet cells and the area they occupied in the mucosa was successfully determined via their combined staining colour by means of threshold classification (Figure 4B). The different mucin types were successfully identified via their different staining colour by means of pixel classification (Figure 4C). Semiautomatic quantification of different mucins was performed in samples of 24 animals. The boxplots (Figure 4D) show the general distribution of the different mucin types throughout the gastrointestinal tract. On average, $8 \%$ sulfomucin, $2 \%$ sialomucin, $40 \%$ neutral mucin,

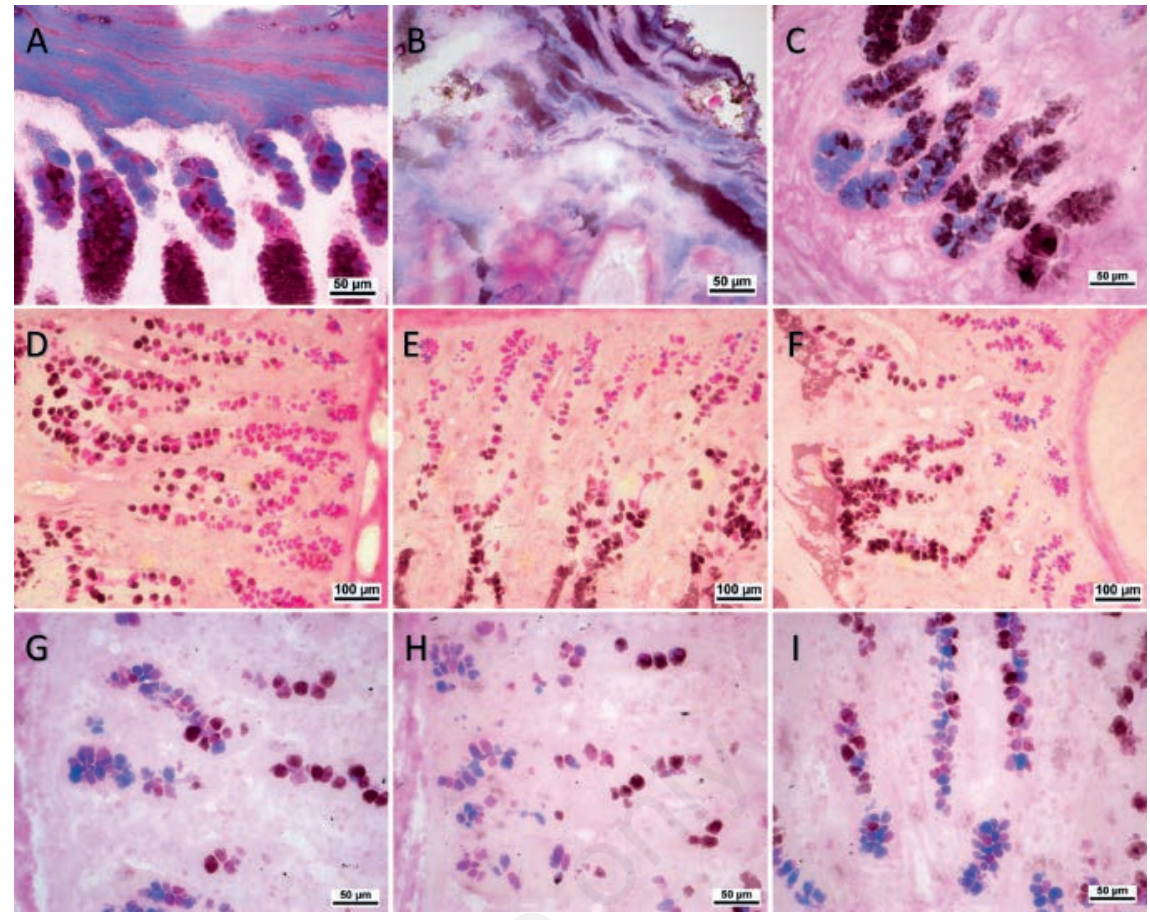

Figure 2. Triple fixation (heat, cold ethanol, bouin) and triple staining (HID, AB, PAS). A) Stomach - cardiac region (surface) with layered appearance of surface mucus. B) Stomach - pyloric region (surface) also with layered appearance of surface mucus. C) Stomach - pyloric region (glands). D,G) Duodenum. E,H) Jejunum. F,I) Ileum.
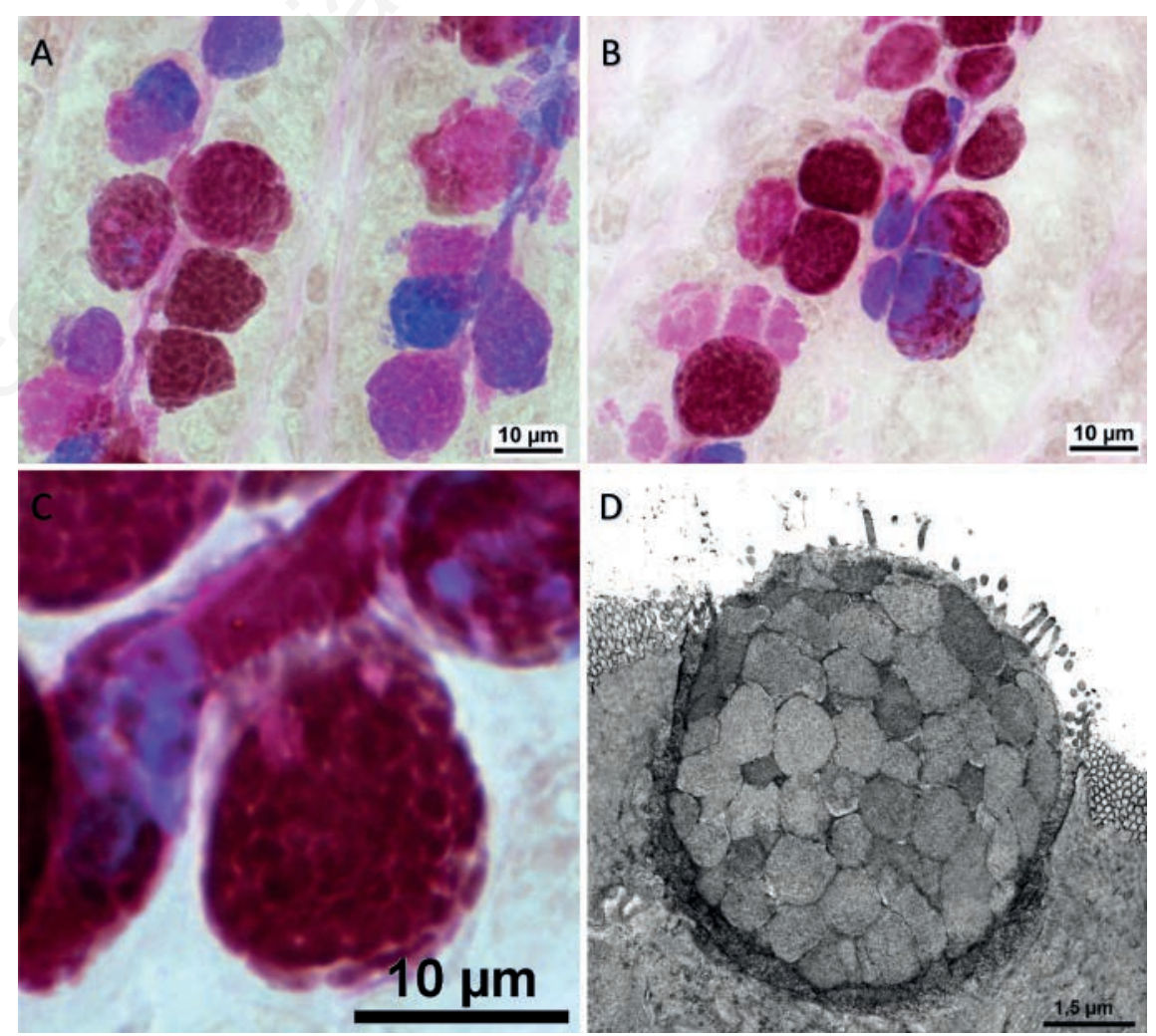

Figure 3. Goblet cell morphology after triple fixation (heat, cold ethanol, bouin) and HID (sulfomucin, brown), AB (sialomucin, turquoise) and PAS (neutral mucin, pink): membrane surrounded mucin droplets are intact within the cells. A-C) Cryo-sections from the ileum; the morphology is comparable to ultrastructural electron microscopical observations in (D), which shows a transmission electron microscopical picture of a porcine intestinal goblet cell from the colon. 
$30 \%$ mixed neutral + sulfomucin and $20 \%$ mixed neutral + sialomucin were found in the examined samples.

\section{Discussion}

The assessment of mucin types via histochemistry and other methods has a long tradition, ${ }^{13-15}$ and although techniques like ELISA, Western blotting as well as the use of lectins or antibodies in mucin detection have their indisputable advantages,${ }^{16}$ histochemistry is frequently used in several disciplines. In histopathology, for example, it facilitates identification of mucin subtypes secreted in various gastric mucosal lesions and subsequent typing of intestinal metaplasia. ${ }^{17-19}$ Also, in nutritional studies histochemistry is used to evaluate quantitative and qualitative characteristics of mucins and how they are influenced by different treatments..$^{20-23}$ The possibility to link histochemical information with micro-anatomical observations is a key advantage but methodological limits, like the influence of fixation, have to be considered. ${ }^{24}$

Since our aim was to study the natural appearance of mucins in the cell and paraffin embedding causes the mucus to shrink, ${ }^{3,7}$ a protocol with frozen sections was to be established. Cohen and colleagues reported their protocol to be suitable for the
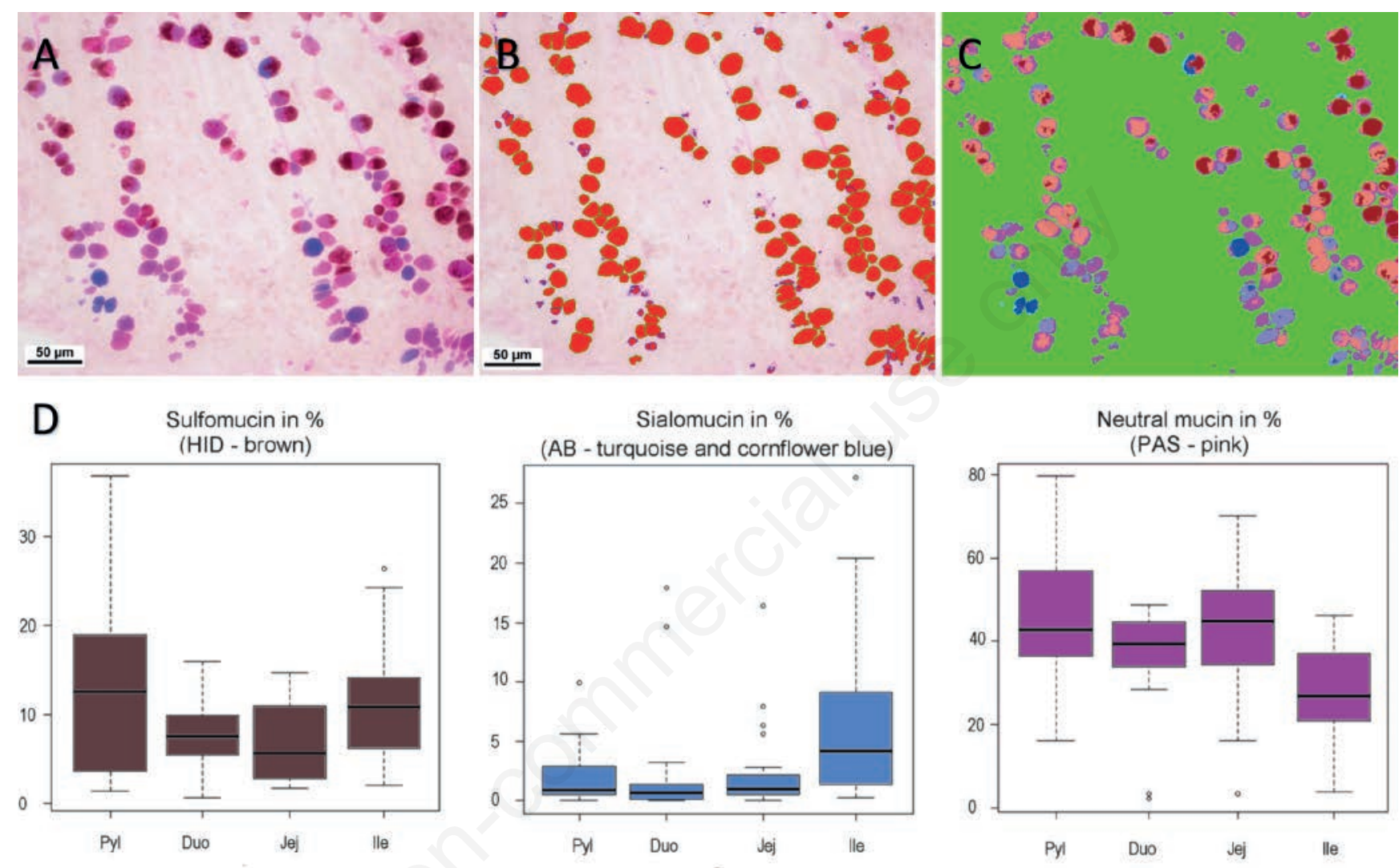

Mixed mucin: neutral + sulfomucin in \% (HID + PAS - pink with brown shade)

Mixed mucin: neutral + sialomucin in \%

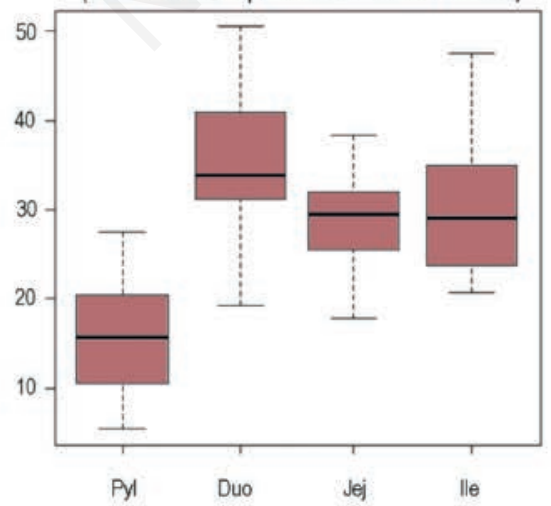

(PAS + AB - violet)

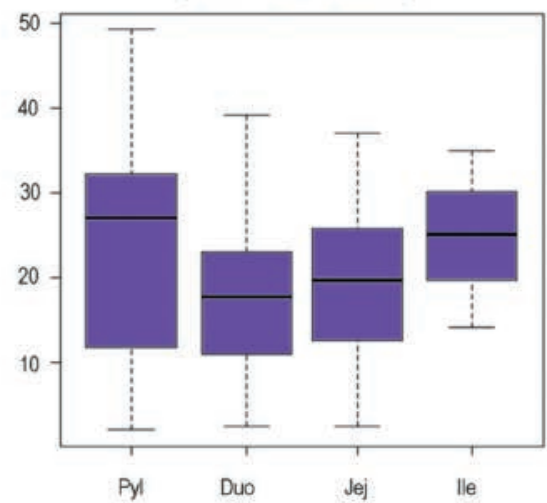

Figure 4. Representative images of how the automatic measurement procedure for different mucins was performed in gastrointestinal samples. A) Jejunum - original picture with triple staining. B) Same picture of jejunum with automatic goblet cell count. C) Same picture of jejunum with mucus quality assessment with an overlay of detected colours. Green: background. D) The boxplots show the general distribution of the different mucin types for pyloric region of the stomach, duodenum, jejunum and ileum (n=24). 
demonstration of the natural appearance of mucus in frozen sections. ${ }^{7}$ Comparing their to our results as well as to images from literature, ${ }^{25}$ reporting to use the protocol of Cohen et al., the mucins seemed to leak out of the goblet cells, forming fuzzy or foamy staining halos around them. One possibility could be that the samples were not appropriately fixed for the target. Goblet cells excrete their mucus according to requirements into the intestinal lumen and meanwhile the mucins are stored in membrane surrounded vesicles in the goblet cell theca, ${ }^{26}$ which was also demonstrated in our transmission electron microscopical evaluation. When these membrane-surrounded compartments are not well preserved during fixation, processing or staining, the result seems to be a "on the spot" formation of mucus, which is washed away or kept in place more or less in its expanded form. In the samples treated with our final protocol, light microscopic morphology resembled ultrastructural electron microscopical observations, with no leakage of mucins from the goblet cells.

Since a wide variety of fixation procedures was tried, it can be suggested that the combination of three fixation steps was the key to success for the target "goblet cell" in this protocol. The first step, dehydrating with heat, is a common practice in histology and described as the simplest form of fixation, precipitating proteins. ${ }^{27}$ The second step, absolute ethanol at $-80^{\circ} \mathrm{C}$, was successfully used by Kagoshima et al., ${ }^{28}$ to demonstrate the mucous gel layer and mucous cells in rat gastric paraffin sections. They observed the effects of ethanol at various temperatures and additionally evaluated the hexose and hexosamine contents contained in the fixative solution after fixation. They found them to be the smallest for ethanol at $-80^{\circ} \mathrm{C}$ and deemed it the most suitable fixative for histological estimation of mucous gel and mucous cells in rat gastric surface mucosa. ${ }^{28}$ The third step, alcoholic Bouin's solution (Gendre's solution), was described to have an enhanced retention of carbohydrates in tissues. ${ }^{27}$

Triple staining with high HID, AB and PAS reaction is very useful in the analysis of mucins and can be employed to identify sulfomucin, sialomucin, neutral mucin and mixtures thereof on one tissue section. ${ }^{12,29}$ The successful evaluation of samples showed that automatic goblet cell quantification as well as the assessment of mucin type distribution within the goblet cell population in the gastrointestinal tract is possible with this protocol. A recent paper comparing various histological protocols for preserving and quantifying the intestinal mucus layer in pigs showed that the relative mucin staining area of colonic crypts corre- lated positively with the thickness of the surface mucus layer. ${ }^{30}$ Since it is difficult to preserve the mucus layer in histological samples, measurement of relative mucin staining area appears to be an attractive parameter. Therefore, a reliable fixation protocol for mucin-producing cells appears to be important in order to maintain their natural morphological properties for correct measurements.

In conclusion, the assessment of mucus quality askes for strictly tested procedures and a good approach seems to be the combination of cryostat sectioning with three subsequent fixation steps.

\section{References}

1. Johansson MEV, Hansson GC. Immunological aspects of intestinal mucus and mucins. Nat Rev Immunol 2016;16:639-49.

2. Johansson MEV, Ambort D, Pelaseyed T, Schütte A, Gustafsson JK, Ermund A, et al. Composition and functional role of the mucus layers in the intestine. Cell Mol Life Sci 2011;68:3635-41.

3. Pelaseyed T, Bergström JH, Gustafsson JK, Ermund A, Birchenough GMH, Schütte A, et al. The mucus and mucins of the goblet cells and enterocytes provide the first defense line of the gastrointestinal tract and interact with the immune system. Immunol Rev 2014; 260:8-20.

4. Kavanaugh D, O'Callaghan J, Kilcoyne M, Kane M, Joshi L, Hickey RM. The intestinal glycome and its modulation by diet and nutrition. Nutr Rev 2015;73: 359-75.

5. Montagne L, Piel C, Lallès JP. Effect of diet on mucin kinetics and composition: nutrition and health implications. Nutr Rev 2004;62:105-14.

6. Wu YB, Ravindran V, Thomas DG, Birtles MJ, Hendriks WH. Influence of phytase and xylanase, individually or in combination, on performance, apparent metabolisable energy, digestive tract measurements and gut morphology in broilers fed wheat-based diets containing adequate level of phosphorus. $\mathrm{Br}$ Poult Sci 2004;45:76-84.

7. Cohen M, Varki NM, Jankowski MD, Gagneux P. Using Unfixed, frozen tissues to study natural mucin distribution. J Vis Exp 2012;3928. doi: 10.3791/3928

8. Rieger J, Twardziok S, Huenigen $\mathrm{H}$, Hirschberg RM, Plendl J. Porcine intestinal mast cells. Evaluation of different fixatives for histochemical staining techniques considering tissue shrinkage. Eur J Histochem 2013; 57:e21.
9. Romeis B. Mikroskopische Technik. [Book in German]. 17th ed. Böck P, editor. München: Urban und Schwarzenberg; 1989.

10. Ueda T, Mittal AK, Fujimori O, Yamada K. HID-AB2.5-PAS and HID-PAS methods for the histochemical analyses of a variety of carbohydrates. Okajimas Folia Anat Jpn 1994;71:51-7.

11. Spicer SS. Diamine methods for differentiating mucosubstances histochemically. J Histochem Cytochem 1965; 13:211-34.

12. Kumari U, Mittal S, Mittal AK. Histological and histochemical investigations of the pharyngeal jaw apparatus of a carp Cirrhinus mrigala. Acta Histochem 2014;116:421-34.

13. Clowes GHA, Owen AG. Metachromatism of mast-cell granules and mucin. J Med Res 1904;12:407-31.

14. Hammarsten O. Studien über Mucin und mucinähnliche Substanzen. [Article in German]. Arch Gesamte Physiol Menschen Tiere 1885;36:373-456. doi: 10.1007/BF0163295615.

15. Hempelmann LH. Staining reactions of the mucoproteins. Anat Rec 1940;78: 197-206.

16. Harrop CA, Thornton DJ, McGuckin MA. Detecting, visualising, and quantifying mucins. Methods Mol Biol 2012; 842:49-66

17. Einstien D, Prathiba, Parijatham, Maheswari. Role of mucin histochemistry in gastric mucosal lesions. Int J Sci Study 2016;4:146-9.

18. Mandal PK, Chakrabarti S, Ray A, Chattopadhyay B, Das S. Mucin histochemistry of stomach in metaplasia and adenocarcinoma: An observation. Indian J Med Paediatr Oncol 2013; 34:229-33.

19. Prasanna LC. Analysis of the distribution of mucins in adult human gastric mucosa and its functional significance. J Clin Diagn Res 2016;10:AC01-4. A

20. Brown DC, Maxwell CV, Erf GF, Davis ME, Singh S, Johnson ZB. The influence of different management systems and age on intestinal morphology, immune cell numbers and mucin production from goblet cells in post-weaning pigs. Vet Immunol Immunopathol 2006;111:187-98.

21. Hedemann MS, Jensen BB, Poulsen HD. Influence of dietary zinc and copper on digestive enzyme activity and intestinal morphology in weaned pigs. J Anim Sci 2006;84:3310-20

22. Piel C, Montagne L, Sève B, Lallès J-P. Increasing digesta viscosity using carboxymethylcellulose in weaned piglets stimulates ileal goblet cell numbers and maturation. J Nutr 2005;135:86-91. 
23. Zhu C, Lv H, Chen Z, Wang L, Wu X, Chen $\mathrm{Z}$, et al. Dietary zinc oxide modulates antioxidant capacity, small intestine development, and jejunal gene expression in weaned piglets. Biol Trace Elem Res 2017;175:331-8.

24. Walsh MD, Jass JR. Histologically based methods for detection of mucin. Methods Mol Biol Clifton NJ 2000;125:29-44.

25. Volynets V, Rings A, Bárdos G, Ostaff MJ, Wehkamp J, Bischoff SC. Intestinal barrier analysis by assessment of mucins, tight junctions, and $\alpha$-defensins in healthy $\mathrm{C} 57 \mathrm{BL} / 6 \mathrm{~J}$ and $\mathrm{BALB} / \mathrm{cJ}$ mice. Tissue Barriers 2016;4:e1208468.

26. Birchenough GMH, Johansson ME, Gustafsson JK, Bergström JH, Hansson GC. New developments in goblet cell mucus secretion and function. Mucosal Immunol 2015;8:712-9.

27. Bancroft JD, Gamble M, editors. Theory andpractice of histological techniques. 6th ed. Philadelphia: Churchill Livingstone Elsevier; 2008.

28. Kagoshima M, Kodaira H, Shimada H. A study on fixatives for the simultane- ous histological estimation of the gastric mucous gel layer and mucous cells in rat gastric surface mucosa].[Article in Japanese. Nihon Yakurigaku Zasshi 1994;104:369-77.

29. Ueda T, Mittal AK, Fujimori O, Yamada $\mathrm{K}$. The utility of Hid-Ab Ph 2.5-Pas and Hid-Pas methods for cytochemical analysis of mucosubstances secreted by fish epidermis. Acta Histochem Cytochem 1994;27:613-7.

30. Röhe I, Hüttner FJ, Plendl J, Drewes B, Zentek J. Comparison of different histological protocols for the preservation and quantification of the intestinal mucus layer in pigs. Eur J Histochem 2018;62:2874.

31. Romeis B. Mikroskopische Technik. 16th ed. München, Wien: R. Oldenbourg Verlag; 1968.

32. Cole PP. The muci-carmin staining method. Proc R Soc Med 1912;5(Pathol Sect):33-5.

33. Harrison PT. An ethanol-acetic acid-formol saline fixative for routine use with special application to the fixation of non-perfused rat lung. Lab Anim
1984;18:325-31.

34. Carnoy JB, Lebrun H. La vésicule germinative et les globules polaires chez les batraciens. [Book in French]. Lierre: Joseph van In; 1897. Available from: http://archive.org/details/lavsiculegermi n00lebrgoog

35. Mota I. Release of histamine from mast cells. In: Rocha e Silva $M$, ed. Histamine and anti-histaminics: Part 1: Histamine, its chemistry, metabolism and physiological and pharmacological actions. Handbook of Experimental Pharmacology book series volume 18/1. Berlin, Heidelberg: Springer Berlin Heidelberg; 1966. doi: 10.1007/978-3662-12016-3 21

36. Sarges J. Histologische Untersuchungen und immunhistochemische Untersuchungen zum Vorkommen und zur Verteilung verschiedener Kollagentypen im Plazentom beim Rind unter besonderer Berücksichtigung des Nachgeburtsa bganges. [PhD Dissertation in German]. Freie Universität Berlin; 1997. 